\section{Transtornos alimentares e obesidade}

Maria Angélica Nunes, José Carlos Appolinario, Ana Luiza Galvão, Walmir Coutinho, organizadores. 2a ed. Porto Alegre: Artmed; 2006

Os autores do livro "Transtornos alimentares e obesidade" realizaram uma façanha poucas vezes repetida no mercado editorial do país: não só publicaram recentemente uma segunda edição, mas enriqueceram a edição de 1998 que já era uma referência na área de transtornos alimentares. Tal feito se deve ao amadurecimento clínico e acadêmico dos autores, representantes dos mais importantes grupos nacionais de atendimento e pesquisa de transtornos alimentares. Nesta edição, 33 capítulos são distribuídos em duas seções: a primeira contém capítulos sobre os transtornos alimentares e, a segunda, sobre a obesidade. O doutor Jason Halford, especialista em neurobiologia do comportamento alimentar, escreve o primeiro capítulo sobre as circuitarias neurais subjacentes à regulação episódica do comportamento alimentar, de novos neuropeptídeos (p.ex, orexinas e peptídeo YY) e da integração de fatores pós-absortivos que determinam o término de uma refeição. Seguem-se vários capítulos essenciais na área: questões diagnósticas, epidemiologia, etiologia, comorbidade psiquiátrica, curso e prognóstico, entre outros. Os capítulos sobre tratamento e os temas acrescidos nesta edição merecem destaque. Embora seja consenso que o tratamento dos transtornos alimentares deva ser feito por uma equipe multidisciplinar, muitas vezes o que se vê são profissionais diferentes agindo isoladamente. Neste livro, os capítulos dedicados ao tratamento enfatizam a real integração de múltiplas abordagens, o que é ilustrado de forma brilhante no capítulo "Psicoterapia dos transtornos alimentares", no qual as autoras explanam detalhadamente a integração de conceitos psicanalíticos, abordagens oriundas da terapia comportamentalcognitiva e a imperiosidade da recuperação ponderal no tratamento da anorexia nervosa. Os novos temas são os transtornos alimentares em homens, transtornos alimentares em crianças e adolescentes e, finalmente, instrumentos para a avaliação dos transtornos alimentares. Pesquisadores e clínicos têm acesso agora às escalas clássicas como o Teste de Atitudes Alimentares (EAT) e Teste de Investigação Bulímica de Edimburgo (BITE), além de outras mais específicas como a Escala de Compulsão Alimentar (BES), Questionário sobre Padrões de Alimentação e Peso, Revisado (QEWP-R) e o Questionário de Imagem Corporal (BSQ), porque elas se encontram na íntegra no anexo ao final do livro. Na seção de obesidade, os capítulos trazem ótimas revisões sobre temas centrais, tais como epidemiologia, etiologia e abordagens terapêuticas (medicamentosas e associadas a mudanças de estilo de vida). Além disso, há capítulos de temas atuais: síndrome metabólica, obesidade infantil e a avaliação psiquiátrica da cirurgia bariátrica.

Todo o conteúdo excelente e atualizado do livro é brindado com um belo trabalho de editoração e diagramação, que auxiliam o leitor com o uso de caixas de chamada ao longo dos capítulos que salientam frases centrais do texto e uma seção de "considerações finais" que se segue ao término de cada capítulo. Assim sendo, o livro é útil para clínicos bem como é indicado para alunos na área da saúde.

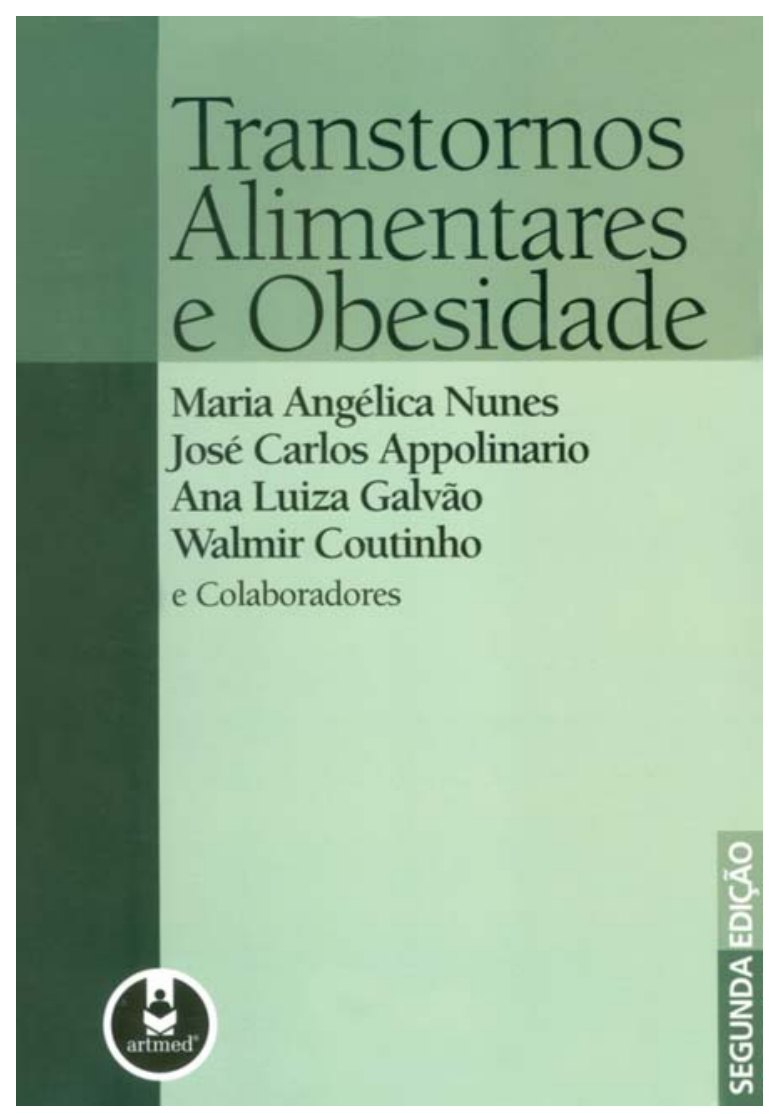

André B Negrão

Grupo Interdisciplinar de Estudos de Álcool e Drogas (GREA) e Instituto de Psiquiatria, Universidade de São Paulo (USP), São Paulo (SP), Brasil 